\title{
Surface Charge Reversal Method for High-Resolution Inkjet Printing of Functional Water- Based Inks
}

Raiden Cobas , * Susset Muñoz-Pérez, Sean Cadogan, Mark C. Ridgway, and Xavier Obradors

Dr. R. Cobas, Dr. S. Muñoz-Pérez, Prof. S. Cadogan. School of Physical, Environmental and Mathematical Sciences. University of New South Wales. Canberra, ACT 2610 , Australia. Email:r.cobasacosta@adfa.edu.au

Prof. M. C. Ridgway.Department of Electronic Materials Engineering. Research School of Physics and Engineering. Australian National University.Canberra , ACT 0200 , Australia

Prof. X. Obradors. Institut de Ciencia de Materials de Barcelona (ICMAB-CSIC). Universitat Autonoma de Barcelona. E-08193, Bellaterra, Spain

Printed electronics is a rapidly growing area of research being explored for the manufacture of large-area and cost-effective electronic devices by the patterned application of functional inks. There are challenges associated with processing the inks compatible with inkjet printing technology and developing efficient methods to successfully obtain the desired features, particularly when it comes to metal and metal-organic complex inks. Here, a reliable method is developed to achieve a sophisticated microstructured pattern using the inkjet printing technique assisted by a surface charge reversal effect. In addition, a procedure is formulated to obtain good quality, stable metal-organic water-based inks compatible with salts of a variety of transition metals and rare earths, without the need for additional volatile solvents. A feasible and water-based ink formulation combined with a simple and noninvasive surface charge reversal treatment constitutes a major step toward the manufacture of high-resolution, inorganic patterned thin films on hydrophobic substrates using inkjet printing. These outcomes lead to the path of effective fusion of inorganic and organic heterointerfaces by simples designing and printing.

\section{Introduction}

The application of inkjet printing (IJP) technology to the deposition of organic and inorganic materials is providing an unprecedented opportunity for the rapid manufacture of large area and cost-effective electronic and functional devices on flexible substrates such as plastic, metals, or even paper. Research on ways to obtain a variety of functional materials using IJP has grown rapidly, leading in recent years to the development of cutting-edge technologies and devices such as: organic light-emitting diode (OLED) displays, printed organic solar cells, $\mathrm{fl}$ exible batteries, logic and memory components including organic fi eld-effect transistors and thin-fi Im transistors, $\mathrm{fl}$ exible displays, sensor arrays, radio frequency identifi cation tags, and superconducting tapes. [1-18]

To cite one recent outstanding application, the Panasonic Corporation unveiled in December 2013 a 56 in. 4K (high-pixel density) organic-inorganic hybrid OLED TV, where all the organic materials were deposited using IJP methods. 
This hybrid TV exhibits properties that are not easily achievable with either organic or inorganic materials alone, such as the best image quality ever, high contrast, fast response rate, high energy efficiency, and with the advantages of being ultrathin and lightweight. [ $16,19]$

Clearly, the manufacture of both organic and inorganic materials using IJP constitutes the next step toward a new generation of advanced materials and modern electronic devices, with a potential multibillion dollar market in the near future. [ 20 ] Therefore, considerable attention has been directed mostly toward the optimization of metal-organic inks, compatible with IJP technology, containing a single metal for direct metallization. [ 21-27 ] Such inks are already commercially available as a consequence of a huge global market desiring cheap inorganic conducting grids.

However, the obtaining of sophisticated hybrid inks blending several metal-organic complex raw materials (HMOC) compatible with both the printer and the substrate is still being researched, and this approach is directly linked to the novel capabilities associated with the use of chemical solution deposition (CSD) to prepare self-assembled complex oxide nanostructures and multilayers under mild processing conditions. [ 28-40 ] Achieving the desired composition and the optimum rheological properties, together with the stabilization of several chemical bonds between organic and inorganic molecules, are critical issues during the manufacture of $\mathrm{HMOC}$ inks compatible with IPJ technology. In addition, the difference between the ink surface tension (ST) and the surface energy of a hydrophobic substrate has a profound effect on the adhesive strength of the complex linkages between the $\mathrm{fl}$ uid and the substrate, causing the ink drop to spread out or stop off during the drying process. [ 41 ] It is, therefore, highly desirable to develop a process for the controlled assembly of inorganic microstructures on nonporous substrates using IJP.

In this article, we present a novel method to successfully obtain a complex microstructured electrical circuit from an HMOC ink using the IJP technique assisted by a surface charge reversal (CR) effect. We also reveal a feasible procedure to obtain HMOC waterbased inks compatible with piezoelectric IJP technology. The excellent rheological properties of the ink together with an original and cost-effective CR surface treatment allow high-quality singlecrystal patterned thin films to be obtained on hydrophobic substrates. The method can be used for deposition of organic and inorganic materials on a diversity of substrates.

\section{Results and Discussion}

\subsection{Substrate Treatment (Surface CR Method)}

There are two approaches currently used to overcome the incompatibility between waterbased ink and hydrophobic substrates: i) decreasing the ink surface energy density using a surfactant and/or low-ST volatile solvents, which inevitably complicate the ink manufacture and stability; or ii) carrying out surface treatments (for instance, plasma or ultraviolet ozone UV / O 3 treatments) that can provide a strong modification of the surface energy in a predefined region of the substrate. [ 42-45] 
Here, we propose a novel approach that is low cost, quick, reversible, and easy to apply, that enables a surface energy increment by coating the substrate with an aqueous solution of branched polyelectrolyte ( $\mathrm{N} \mathrm{HCH} 2 \mathrm{CH} 2$ ) $\times[\mathrm{N}(\mathrm{CH} 2 \mathrm{CH} 2 \mathrm{NH} 2) \mathrm{CH} 2 \mathrm{CH} 2$ ] y containing ringopening primary, secondary, and tertiary amine groups in an approximate ratio 1:2:1, with a molecular weight of $70000 \mathrm{~g} \mathrm{~mol}-1$.

In a dilute aqueous solution, with a pH between 5.5 and 6 , about $50 \%$ of these groups are protonated. [ 46-51] Consequently, a thin layer of this polyethylenimine (PEI) solution readily adheres to a negatively charged surface, causing the surface charge neutralization and subsequent $C R$, as shown schematically in Figure 1 a.

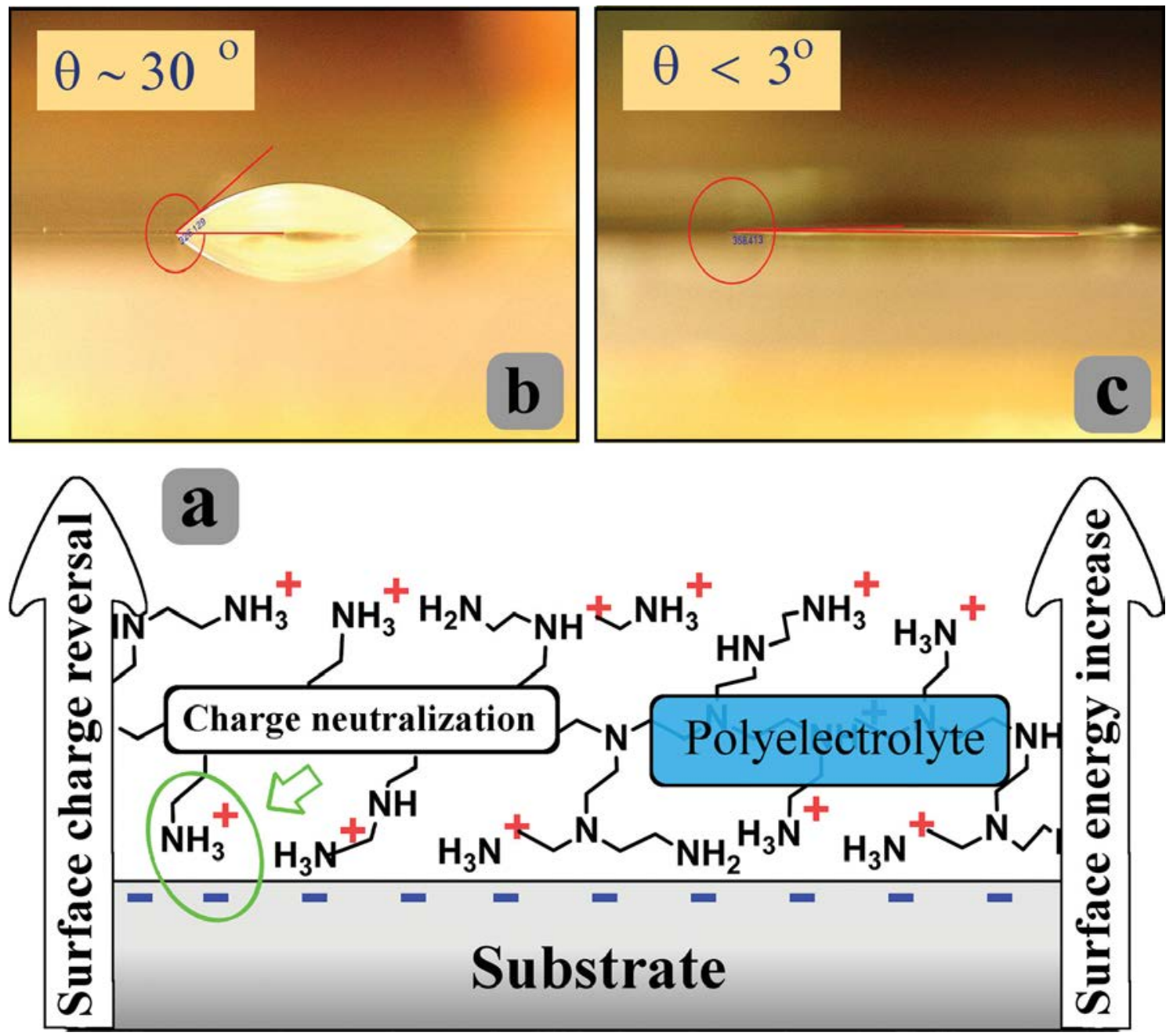

Figure 1. a) Schematic representation of surface CR process due to a $50 \%$ protonated PEI layer. Contact angle of water drop on b) untreated glass surface and c) treated glass surface

To illustrate the surface energy modifi cation, two drops of water with a volume of $0.5 \mu \mathrm{L}$ were placed on untreated (Figure $1 \mathrm{~b}$ ) and treated glass substrates (Figure $1 \mathrm{c}$ ) and their equilibrium contact angles $\theta$ (formed at the three-phase boundary where the liquid, gas, and solid meet) were measured. In the case (1c) where the CR process occurred, the surface energy increased, reducing the contact angle almost to zero and modifying the fluid mobility. 
In order to demonstrate the potential of CR surface treatment to assist the IJP technique, the wettability of an HMOC water-based La $0.85 \mathrm{Ag} 0.15 \mathrm{MnO} 3$ (LAMO) solution jetted on glass and LaAIO 3 (LAO) single-crystal substrates was investigated. A silver-doped manganite ink was chosen because the final material, after transformation to a solid, displays ferromagnetic, metallic behavior, colossal magnetoresistance, and magnetocaloric effect at room temperature. [ 52-55 ] Nevertheless, the ink formulation proposed here can be applied to several elements of the periodic table due to the water compatibility with many metals and rare-earth salts, without the need for additional volatile solvents. More details about the ink processing are included in the next section.

\subsection{Ink Formulation}

The water-based LAMO ink stability was achieved due to repulsion forces, mainly of electrosteric origin, between chelates homogenously dispersed in a nonionic polymer. A water-based solution of ethyldiaminetetraacetic acid (EDTA) was used to chelate the metal ions from the salts $\mathrm{La}\left(\mathrm{NO}_{3}\right) 3 \times 6 \mathrm{H} 2 \mathrm{O}, \mathrm{Mn}(\mathrm{CH} 3 \mathrm{COO}) 2 \times 4 \mathrm{H} 2 \mathrm{O}$, and $\mathrm{AgNO} 3$. The major advantage of using EDTA is that it forms stable multidentate negatively charged complexes with almost all metals and rare earths.

Once the chelating process was completed, the viscosity was adjusted using an emulsifi er/stabilizer water-soluble polymer. Sometimes, partial or full chelate charge neutralization due to the addition of anionic or cationic polymers can bridge individual particles leading to aggregation. Therefore, in order to achieve the desired viscoelastic properties and prevent the particles from getting too close and thus experiencing attractive forces, nonionic polyvinyl alcohol (PVA) was added to the solution. As a result, particles with dimensions of $\approx 10 \mathrm{~nm}$ formed spontaneously in the first few minutes of the process.

To reduce the liquid-air interface ST from $\approx 70$ to $30 \mathrm{mN} \mathrm{m} \mathrm{-1,} \mathrm{a} \mathrm{nonionic} \mathrm{surfactant,} \mathrm{Triton} \mathrm{X-}$ 100 , was added to the solution. It is known that to achieve low ST and allow the fluid to evaporate and cure quickly the addition of high concentrations of volatile solvents is recommended. However, we observed that the addition of methanol to the ink has a negative effect, in favor of a micellization process. Alternatively, the Triton X-100 concentration has a direct consequence on its solubilization as individual surfactant monomers or in the formation of undesired micelles; however, the micelles only form when the concentration of surfactant is greater than the critical micelle concentration.

The aggregation process was investigated by particle size inspection to gain insights into the main interactions present in the hydrocolloid dispersed phase. Several particle size measurements were performed to determine the effect of gradual increments of PVA and Triton X-100 on the ink stability. The main result obtained was a well-defined frontier between a homogenous ink with a particle size average of $10 \mathrm{~nm}$ ( Figure 2 a) and the aggregation process (Figure 2 b) at 25 wt\% of PVA and 0.08 wt\% of TritonX-100 concentrations. Above these values, the particle size moves progressively over $10 \mathrm{~nm}$. In addition, the particles start to aggregate, due to attractive interactions, and the unstable colloidal system forms flocs which can reach sizes between 0.1 and $5 \mu \mathrm{m}$. 

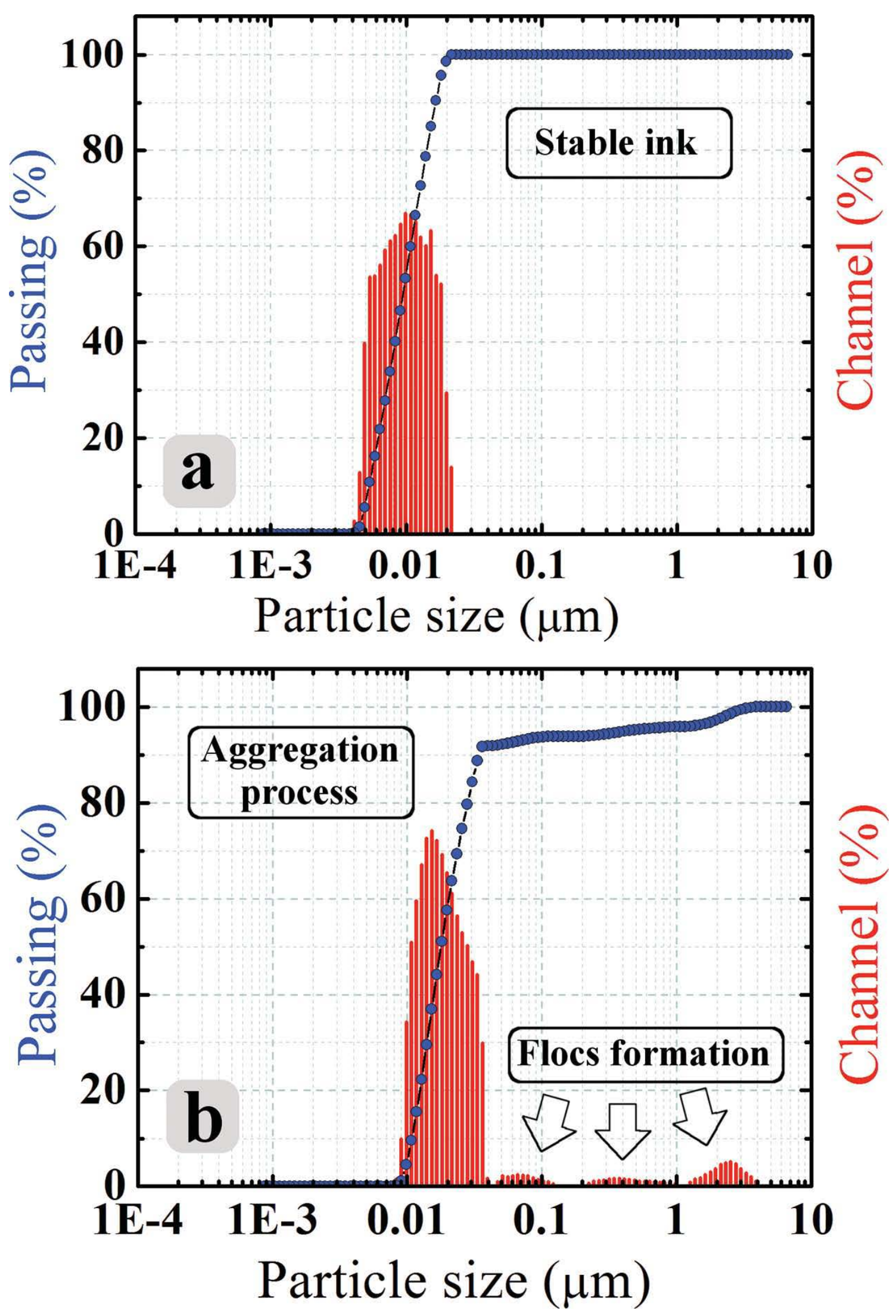

Figure 2. a) Stable Ink with particle size average of $10 \mathrm{~nm}$. b) Unstable Ink showing particle aggregation with sizes between 0.1 and $5 \mu \mathrm{m}$.

In particular, it was found that the quantity of water available is an important factor in longterm stability. Furthermore, small variations in interfacial tension have an immediate effect on 
the stability, which suggests that the forces driving the colloidal system are strongly dependent of the water/surfactant ratio and ink molarities.

The use of low concentrations of PVA provides an ink with both excellent elasticity and adhesive properties. However, improving the viscosity to piezoelectric inkjet optimum values, [ 56 ] between 5 and 10 centipoises (CP), requires an increase in the concentration of PVA, which is unfeasible because it can quickly lead to ink instabilities. To resolve this situation, polyethylene glycol (PEG) with a molecular weight of $400 \mathrm{~g} \mathrm{~mol}-1$ was added to the solution. In the appropriate concentrations, PVA and PEG are effective modifi ers of the ink's viscoelastic properties without deteriorating the repulsion forces inside the fluid, allowing a maximum viscosity value of $7 \mathrm{cP}$. Around $5 \mathrm{cP}$, the polymers network provides excellent electrosteric stabilization to the chelate and prevents the particles from getting close to the range of van der Waals attractive forces over periods of months.

\subsection{Ink Wettability}

The LAMO ink wettability was tested by printing the entire surface and a lower-case letter " $\mathrm{e}$ " on untreated and CR-treated glass substrates (see Figure 3 ). We used a material deposition system based on piezoelectric inkjet technology (Dimatix DMP 2800). The ink was jetted with a 10-pL cartridge having 16 nozzles with a nominal opening of $21 \mu \mathrm{m}$.

It is well known that hydrophobic surfaces repel water molecules; hence, if the liquid does not wet the surface, a large contact angle will be formed, resulting in the formation of small features. However, if the drop does not evaporate or cure quickly the fluid starts to bead and the pattern breaks into individual spots, as observed in Figure 3 a,b. In contrast, a small contact angle is advantageous to obtain an uninterrupted flow with good adhesion to the surface, but this condition allows the liquid to spread out unrestrained and fails to delineate high resolution patterns.

A balance between a low contact angle and keeping the pattern from expanding freely was observed in the surface where the CR treatment was carried out (see Figure $3 c$,d). This result is attributed to the ability of the cationic polyelectrolyte (tightly adhered on the substrate) to coordinate with the ink anionic metal-complex molecules. These chemical bonds play an important role in the spot size control, being strong enough to prevent the liquid from spreading out, achieving the desired pattern with high resolution (schematic representation in Figure 3e). The results of this test reveal that: i) the water-based HMOC ink proposed can be reliably jetted using the piezoelectric IJP and ii) the desired pattern only emerges in the treated substrate due to the excellent surface-wetting properties that the CR method provides. 

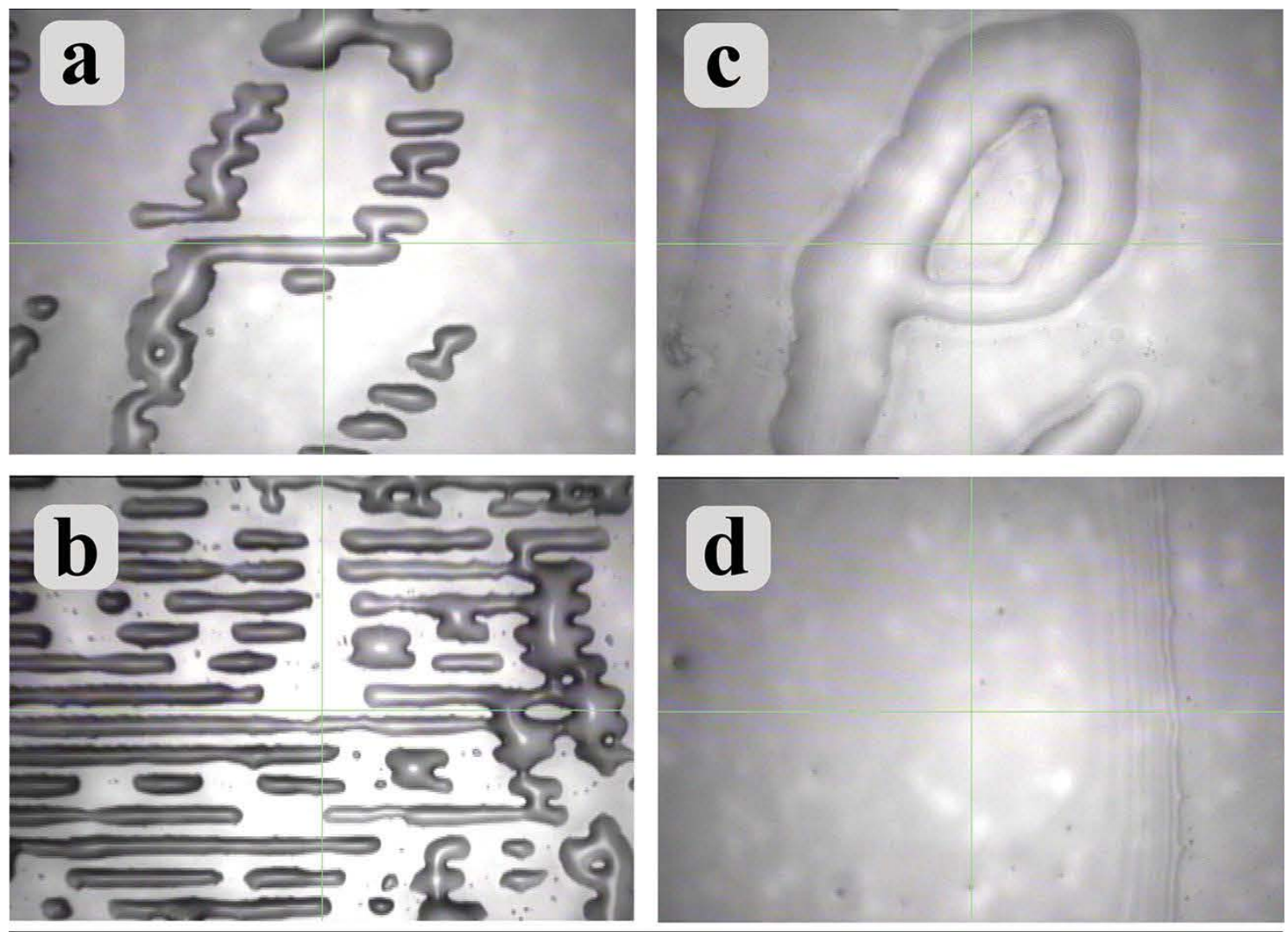

d

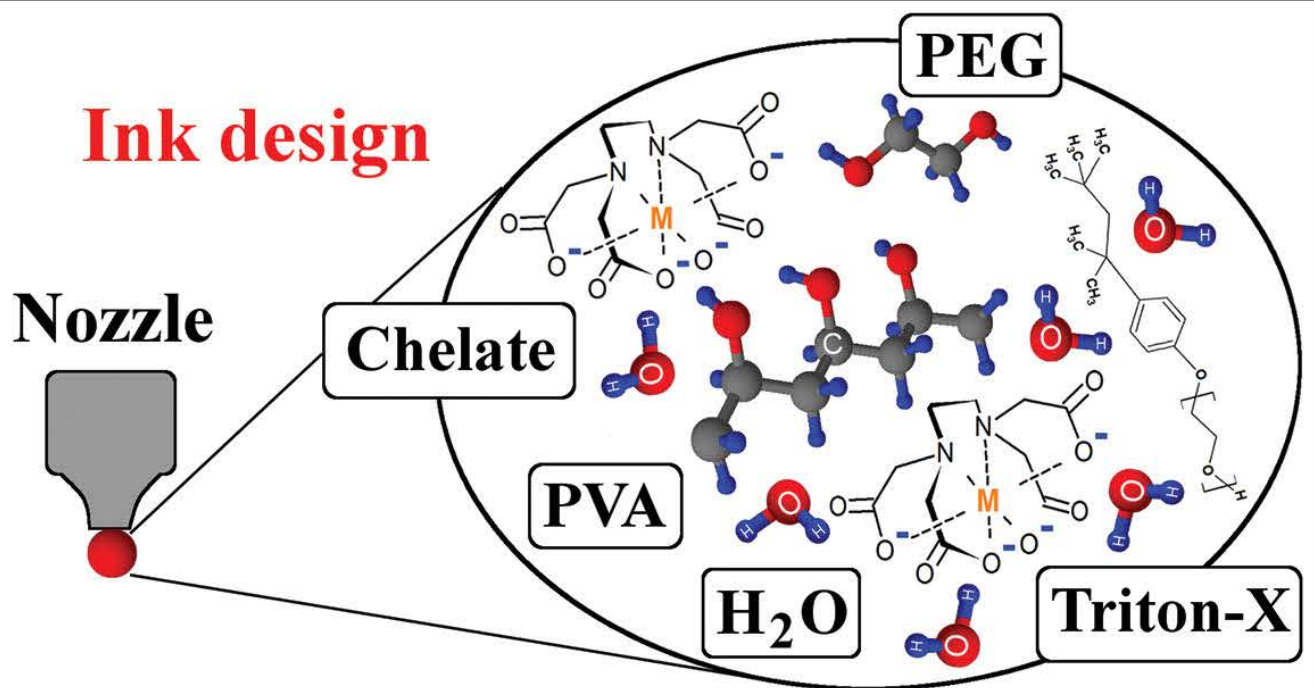

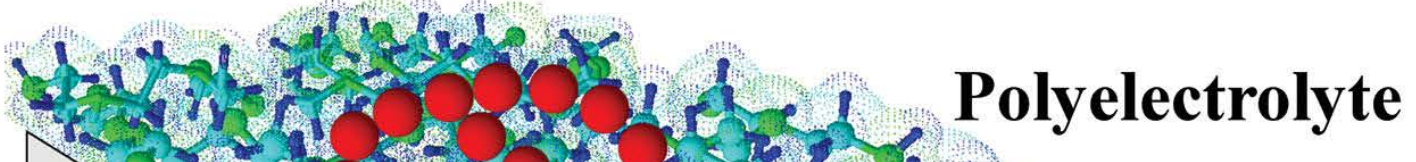

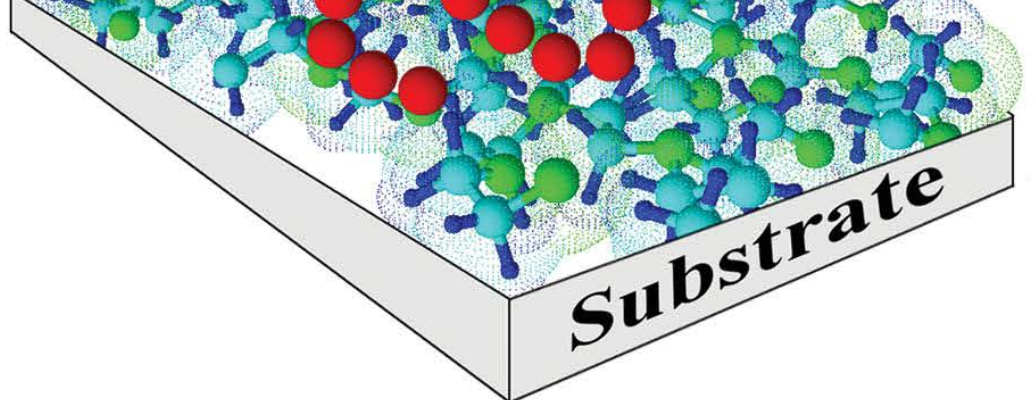


Figure 3. a) Lower-case letter " $e$ " printed on untreated substrate.b) Untreated substrate printed "completely". c) Lowercase letter " $e$ " printed on treated substrate. d) Treated substrate coated completely with only a small fringe uncovered on the right-hand side for better visualization. e) Schematic representation of polyelectrolyte layer on the substrate and ink design.

\subsection{Spot Size Control}

Controlling spot size is a critical point for the application of IJP to an industrial manufacturing process. To demonstrate the excellent spot size control provided by the ink and the CR method, we designed a framework with features ranging from 28 to $300 \mu \mathrm{m}$. This framework could be applied to the manufacture of a magnetic field microarea sensor or a capacitive touch screen, depending on the deposited material properties. The design has 136 rectanglessensors-interconnected in parallel (see the main panel of Figure 4 a) enclosed with other small features covering a total area of $4 \mathrm{~cm} 2$.

Since the scope of this experiment focuses on the drop control, placement accuracy, and surface-wettability properties provided by the method, all the sensors, conducting grid, numbers, and name of the authors were printed using the same ink. This time, we used a 1-pL cartridge having 16 nozzles with a nominal opening of $9 \mu \mathrm{m}$.

The printer is equipped with a drop imaging system (drop watcher) that allows observation and recording of events during drop formation on the print-head nozzles and the trajectory of the drops after ejection. Figure $4 \mathrm{~d}$ shows captured frames of a video taken during the test of the LAMO ink jetability. When the drop leaves the nozzle, it has a small, thick tail. At a distance of approximately $600 \mu \mathrm{m}$, the drop has a perfectly round shape. Under these experimental conditions, the small spot size achieved on a treated glass was $20 \mu \mathrm{m}$ (see Figure $4 \mathrm{e}$ ).

The optical micrograph images surrounding the main panel (designed circuit) in Figure 4 a were taken from the top of the circuit printed on a treated glass substrate. Figure $4 \mathrm{~b}, \mathrm{c}$ shows two different tests where the eight small legs connecting each sensor with the main grid were printed with resolutions of 26 and $41 \mu \mathrm{m}$, respectively. The outstanding control on the drop position and mobility that this method offers enables the determination of the correct amount of overlap (between $25 \%$ and $40 \%$ ) to create precise microlines of different sizes without the wavy edge effects. As a result, curved outlines of different types of font letters and numbers in microscopic scale are possible; see, for instance, the bottom of Figure 4 a where a superposition of several frames reveals some authors' names.
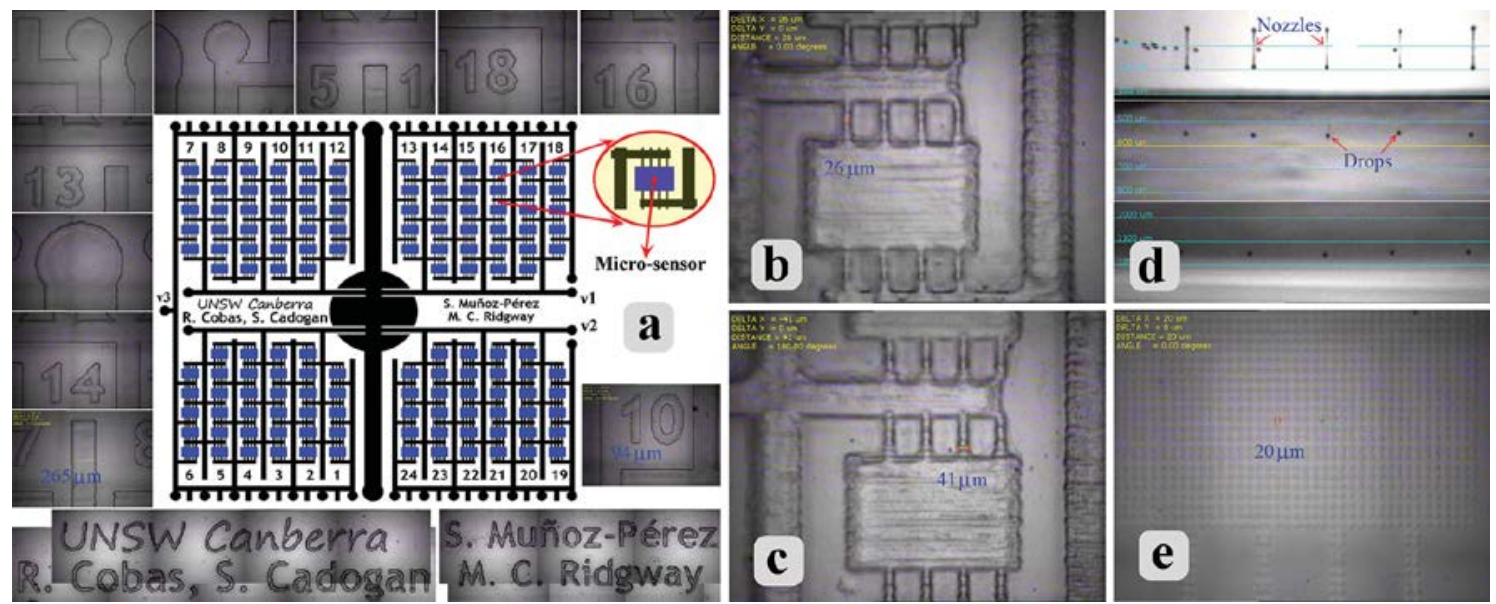
Figure 4. a) Design of a circuit with 136 microsensors connected in parallel. The optical micrograph images surrounding the main panel were taken from the circuit printed on a CR-treated glass substrate using the LAMO ink. b) Optical micrograph image of a sensor with 26- $\mu \mathrm{m}$ features. c) Optical micrograph image of a sensor showing $41 \mu \mathrm{m}$ feature. d) Frames of a video taken during the testing of the LAMO fl uid using a Dimatix printer model DMP 2800. e) Optical micrograph image showing a spot size of $\mathrm{H} 20 \mu \mathrm{m}$ with a center-to-center distance of $30 \mu \mathrm{m}$, achieved with a LAMO ink on a CR-treated glass substrate.

Beyond its low cost and originality, this method has an advantage over the traditional surface treatments since a new variable is introduced to control the spot size and resolution: the electrostatic forces and chemical bonds that immediately link the substrate and the ink. These attractive forces increase the adhesive strength, restraining the fluid mobility and, as a consequence, the ink viscosity "loses" the dominant role. Therefore, low-viscosity water-based inks can also be prepared for thermal IJP technology. The proposed CR method is also a very effective way of preventing the non adsorptive behavior of nonporous substrates. Due to the hydroscopic character of the thin layer of dehydrated polyelectrolyte, a drop of water deposited on top is quickly absorbed. Hence, the ink cures and dries easily at room temperature. We observed that slightly heating the substrate to $35{ }^{\circ} \mathrm{C}$ also has a positive effect, further reducing the spot size and increasing the resolution.

\subsection{Printing on a Single-Crystal Substrate}

The same circuit (without changing the experimental conditions) was printed on a CR-treated $25 \mathrm{~mm} \times 25 \mathrm{~mm} \times 0.5 \mathrm{~mm}$ LAO, $\left(\begin{array}{lll}1 & 0 & 0\end{array}\right)$ oriented substrate, purchased from MTI Inc. The sample was fired at $870^{\circ} \mathrm{C}$ for $10 \mathrm{~min}$ in air. Figure $5 \mathrm{a}$,b shows optical micrograph images taken from the same location before and after annealing the sample, respectively.
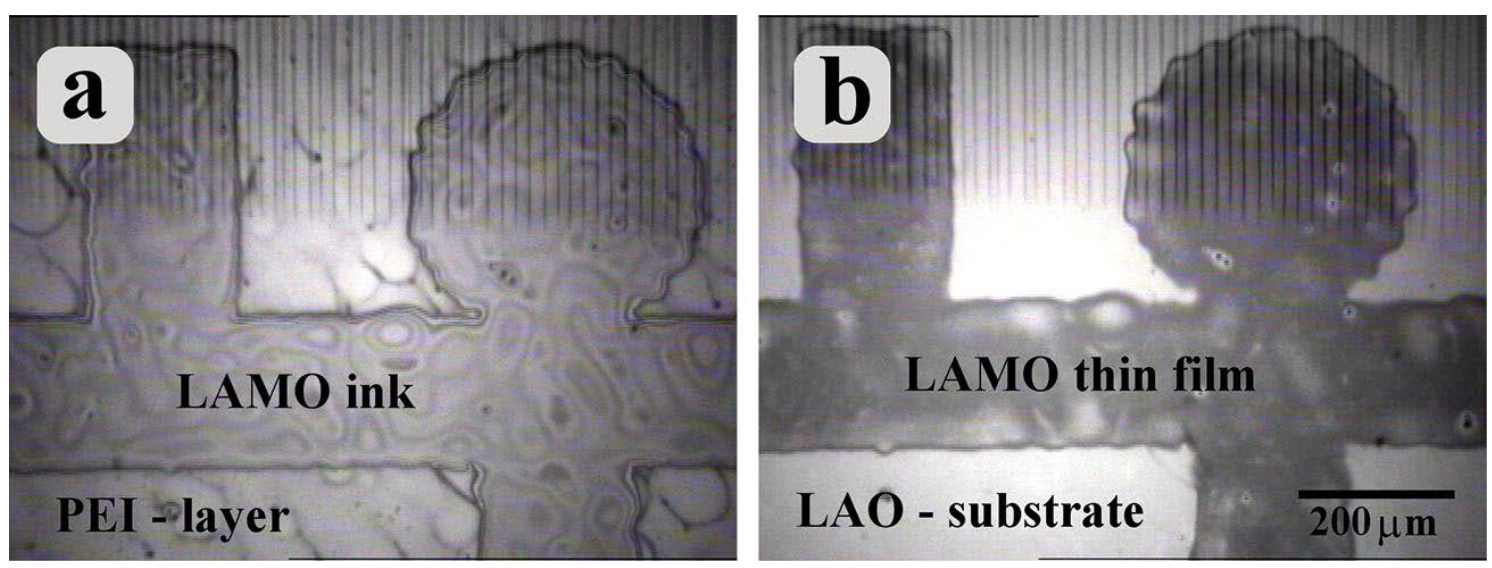

Figure 5. Optical micrograph image of a circuit section a) before and b) after annealing.

The solid pattern that is left after the organic materials evaporate has been affected weakly by the natural "coffee ring" or capillarity flow effects. [ 57,58 ] The result was a thin-film semitransparent to the naked eye (see Figure 6 a). The film thickness was determined to be in the range $40-45 \mathrm{~nm}$ (see inset of Figure $6 \mathrm{~b}$ ), which allows the light to pass through and produce the semitransparent behavior. 


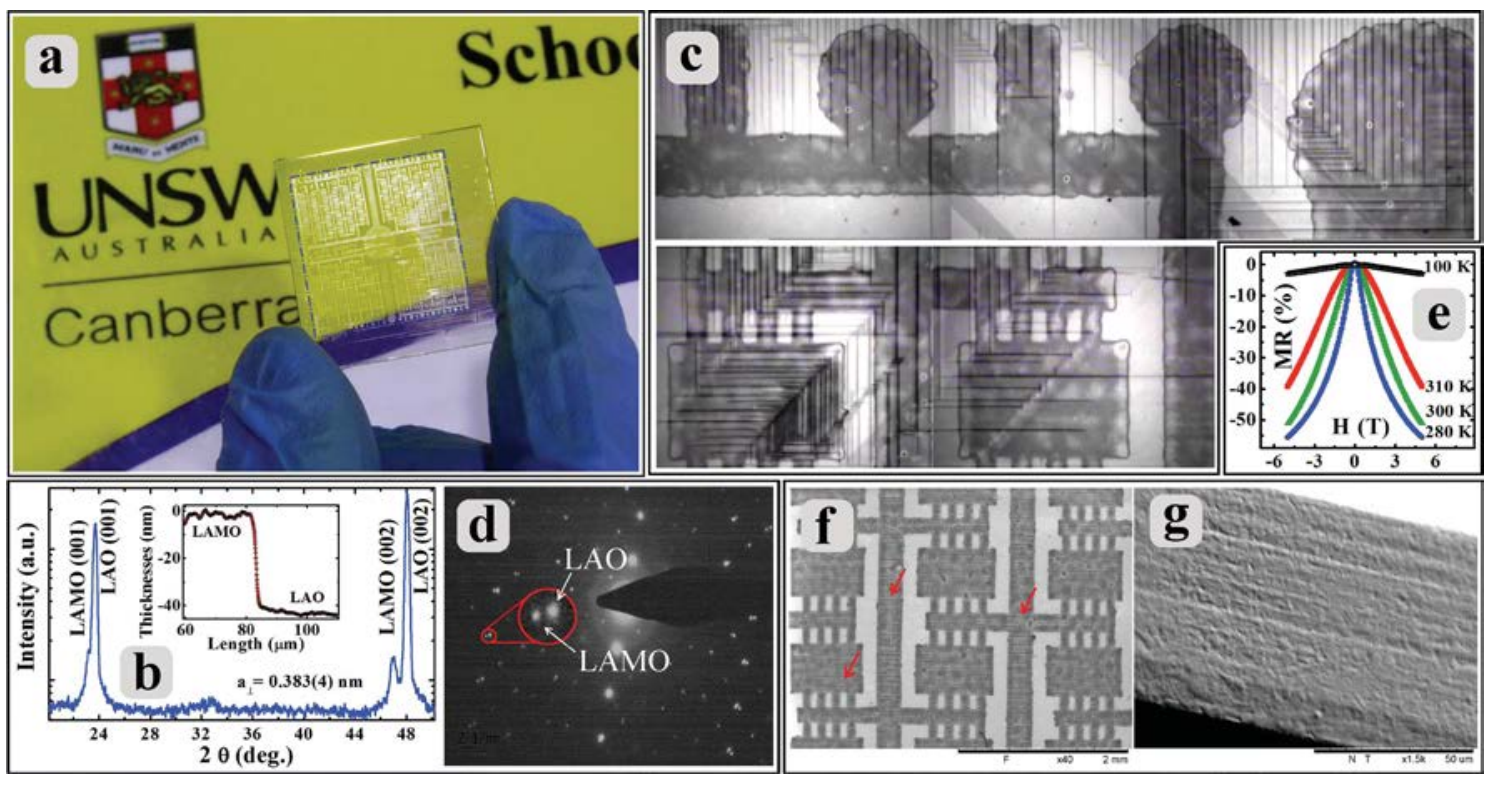

Figure 6. a) Photograph of the semitransparent LAMO circuit grown on LAO single-crystal substrate which has both sides polished and a thickness of $0.5 \mathrm{~mm}$. b) X-ray diffraction pattern showing the epitaxial growth of the LAMO film on LAO substrate (inset showing the thin-fi Im thickness measured). c) Optical micrograph images with the focal point on the LAO surface. d) Electron diffraction from the substrate and the fi Im confi rming the epitaxial growth. e)

Magnetoresistance of the fi Im at different temperatures as a function of applied magnetic fi eld. $f$ ) SEM image showing that the formed pattern is well interconnected across the entire surface. g) SEM image using secondary electrons showing the topography of the thin fi Im.

Figure $6 \mathrm{c}$ shows optical micrograph images focusing on the substrate surface. The LAO microstructural details for the $\left(\begin{array}{lll}1 & 0 & 0\end{array}\right)$ oriented domains were well revealed as a background of vertical and horizontals lines partially covered by the patterned LAMO thin film. It was expected that the fluid tends to spread on these regions since the molecules on the surface of a drop cannot align into their lower energy state as they are disrupted by the rough surface. [ 43 ] The observed pattern on top of a $\mathrm{fl}$ at and single-oriented domain (lower rugosities) does not differ from those that rest on a mixture of tilted and multistep microdomains, which have noticeably higher rugosities. These results clearly show the important role that the chelatepolyelectrolyte interactions play, confi ning the drop to a fixed size and attaching it firmly to a predetermined position on the substrate. This is, therefore, a powerful approach that yields microarchitecture films with good positioning of individual layers independent of the substrate topology.

The crystal structure of the patterned thin fi Im was confirmed by X-ray diffraction. Only the ( 0 0 I) diffraction peaks from the LAMO structure were observed in the X-ray diffraction pattern (main panel of Figure $6 \mathrm{~b}$ ), which indicate that the film grew epitaxially. In addition, electron diffraction from the substrate and the film also proves the epitaxial growth of LAMO on LAO (see Figure $6 \mathrm{~d}$ ).

The temperature dependence of the magnetotransport properties was also investigated (Figure 6 e). The negative magnetoresistance values calculated as $M R(\%)=100 \times\{(\rho(H)-\rho(0)) /$ $\rho(0)\}$, where $\rho(0)$ is the resistivity in the absence of an applied magnetic field. For an applied magnetic field of $5 \mathrm{~T}$, the MRvalue is $-56 \%$ at $280 \mathrm{~K}$. The obtained colossal magnetoresistance is also a sign of a high-quality epitaxial growth, and it is comparable to the best values obtained in thin films prepared either by vacuum deposition or by CSD. [ 52,55,59,60 ] 
A preliminary study performed by scanning electron microscopy (SEM), revealed that the formed pattern is homogenous and very well interconnected across the entire surface. However, depending on a variety of experimental conditions, a slight scalloping effect may eventually occur. Figure $6 \mathrm{f}$ shows a particular case where the circuit was printed on a substrate maintained at a temperature of $50{ }^{\circ} \mathrm{C}$. The scalloping effect reveals itself as superficial horizontal lines from the SEM images; a few of these lines are marked with arrows. Note that these boundaries may form quite early during the printing process because a printed continuous line, on a hot substrate, could dry in a very short period of time. Consequently, the diffusion process between two adjacent frames occurs partially. In this specific situation, the scalloping effect takes place. We observed that a uniform match and a homogenous surface are achieved relatively easily by slightly tuning the following parameters: a) increasing the fi ring frequency (up to $5 \mathrm{kHz}$ ), optimizing the water and PEG concentrations, b) decreasing the PVA and/or PEI concentration, and c) adding water-miscible humectants liquids as ethylene glycol, or simply increasing the humidity and decreasing the substrate temperature. Figure $6 \mathrm{~g}$ shows a SEM topography analysis from a portion of the circuit using secondary electrons. The photograph corroborates the high quality surface morphology, preventing the scalloping effect by adding a small amount of ethylene glycol to the ink.

\section{Conclusion}

In summary, a semitransparent electric circuit covering a large area with 136 colossal magnetoresistive microsensors connected in parallel was fabricated using IJP technology, assisted by a CR method. This semitransparent single-crystal pattern made of silver-doped manganite La $0.85 \mathrm{Ag} 0.15 \mathrm{MnO}$, thin film with a thickness of $40 \mathrm{~nm}$, constitutes a major step toward developing a novel hard disk read/write multiple-head device. This article also details the process required to obtain good-quality, stable hybrid metal-organic water-based inks compatible with salts of a variety of transitions metals and rare earths. The formulation of a feasible water-based HMOC ink compatible with a piezoelectric material printer, as well as substrates with a wide range of surfaces energies opens an original and entirely new opportunity to obtain inorganic materials on hydrophobic substrates using IJP technology.

This is the first time that an HMOC silver-doped manganite ink has been transformed into a solid pattern on a hydrophobic substrate with such a high level of complexity and quality using the IJP technique. This big step forward was achieved due to the obtaining of an ink's formulation compatible with IJP piezoelectric technology combined with the advantages that the surface CR method offers, such as: I) the substrate's surface is not permanently modified during the CR treatment and can be washed with water and reused; II) the method allows the direct printing of high-resolution microlines and curves based on metal-organic solutions; III) it can be applied to the manufacture of high-quality inorganic single-crystal thin films on nonporous substrates; IV) allows the controlled assembly of inorganic microstructures independent of the substrate topology; and V) make possible the control of the ink mobility with an excellent spot size and resolution due electrostatic forces and chemical bonds. Since the substrate is coated with a protonated-organic material, the method can also be used for functional organic materials coatings. 
These outcomes lead to the effective fusion of inorganic and organic heterointerfaces using IPJ technology. The unification of a fabrication process to achieve organic/inorganic heterojunctions can save time, significantly reduce costs, and improve the final quality and performance.

\section{Experimental Section}

Processing of HMOC Ink: The reagents $\mathrm{La}(\mathrm{NO} 3) 3 \times 6 \mathrm{H} 2 \mathrm{O}, \mathrm{Mn}(\mathrm{CH} 3 \mathrm{COO}) 2 \times 4 \mathrm{H} 2 \mathrm{O}, \mathrm{AgNO} 3$ , PVA (with mixed molecular weight ranging from 12000 to $24000 \mathrm{~g} \mathrm{~mol}-1$, composed mainly of 1,3-diol linkages [ $\mathrm{CH} 2 \mathrm{CH}(\mathrm{OH}) \mathrm{CH} 2 \mathrm{CH}(\mathrm{OH})$ ]) and aqueous PEG (400 $\mathrm{g} \mathrm{mol}-1)$ were purchased from Sigma-Aldrich Corporation and used as received. The solution containing the acetate and nitrate salts, EDTA, PVA, PEG, and Triton X-100 was prepared as follows. The materials were placed in a $20-\mathrm{mL}$ round-bottom boiling $\mathrm{fl}$ ask and mixed in the order and ratio described below. The solution was stirred at $50{ }^{\circ} \mathrm{C}$ for $30 \mathrm{~min}$ between each additive. To obtain an $\mathrm{HMOC}$ ink with good chemical-physical properties and stability, there are certain limits in the additive concentrations that must be taken into consideration. The optimum values in wt\% obtained during the preparation of $10 \mathrm{~mL}(0.05 \mathrm{~mol})$ LAMO solution were: Milli-Q water (15\%), EDTA (50\%) plus metal organic salts, PVA (5\%), PEG (30\%), and Triton X-100 (0.01\%). The EDTA and PVA raw materials were used in solution. The EDTA solution was prepared by mixing 0.01 $\mathrm{mol}(70 \%)$ and $0.1 \mathrm{~mol}(30 \%)$ aqueous solutions purchased from Convol. The PVA solution was prepared by stirring $20 \mathrm{~mL}$ of water at $75{ }^{\circ} \mathrm{C}$ containing $98 \%$ hydrolyzed PVA ( $1 \mathrm{~g}$ ). The fi nal LAMO solution with an ST $\approx 30 \mathrm{mN} \mathrm{m}-1$, viscosity of $5 \mathrm{cP}$, and $\mathrm{pH} 6.5$ was stored for three months and no change in the particle size was observed.

Surface Treatment: PEI with average $\mathrm{MW} \approx 70000 \mathrm{~g} \mathrm{~mol}-1$ was supplied in the form of 35-40 wt\% in $\mathrm{H} 2 \mathrm{O}$, with a viscosity between 400 and $900 \mathrm{cP}$, and a pH of 12, from which a $50 \mathrm{ppm}$ solution was prepared containing methanol $(70 \%)$ and Milli-Q water (30\%). The substrates were ultrasonically cleaned in acetone, immersed into Piranha solution [ 61 ] at room temperature for $5 \mathrm{~min}$, rinsed with Milli-Q water and dried under a stream of $\mathrm{N} 2$ (g). Then, the $50 \mathrm{ppm}$ PEI solution was fi Itered and deposited on the substrates at $4000 \mathrm{rpm}$ for $8 \mathrm{~s}$ using a VTC-100A programmable spin coater. This layer can also be deposited by dip-coating, spreadcoating, or simply immersion and adsorption from solution. The surface treatment is based on the electrostatic attraction between liquid and solid phases with opposite charges.

This phenomenon has long been known to be important factor in the adsorption of organics and polyelectrolytes [ 62 ], but it has rarely been studied for complex inorganic layer formation. [ 51 ] Thin-Film Deposition : A DMP 2800 material deposition system from Dimatix Corporation was used to print the LAMO ink. To avoid clogging of the print-head nozzles, the ink was prefi Itered through a Whatman nylon membrane with a $0.25-\mu \mathrm{m}$ pore size. The printhead was maintained at room temperature. A consistent and stable operation window for microdrop generation was selected by adjusting addressable jetting parameters such as fi ring frequency $(2 \mathrm{kHz}$ ), nozzle voltage (between 10 and $16 \mathrm{~V}$ ), meniscus vacuum (2.5 psi), and a modifi ed Dimatix model fl uid waveform. The waveform pulse had a maximum peak occurring at $2.49 \mu \mathrm{s}$, with a length of $2.17 \mu \mathrm{s}$, and a slew rate slope of 1.23 . Another $67 \%$ minor peak initiates at $4.67 \mu$ s and lasts for $1.98 \mu$ s, then slopes to $27 \%$ and recovers the next pulse. The 
drop images were recorded with a monochrome CCD high-speed camera, on bright background illumination with a stroboscopic LED array that is synchronized with the camera.

Characterization : Particle size analysis was carried out using a dynamic light scattering nanotrac system from Microtrac Inc. The results were reported as the average of three independent runs. The ST values were measured using a tensiometer Sigma 700 based on the

Wilhelmy plate principle and the kinematic viscosity was monitored using two Cannon Fenske routines (viscosimeters \#75 and \#100) and a programmable Bohlin viscosimeter (model VISCO88BV). The $\mathrm{pH}$ of the solutions was measured using a portable $\mathrm{pH}$ meter model WP-80. The surface morphology of the thin film was analyzed using a Hitachi Analytical Table-Top Microscope/Bench-top SEM TM3030.

X-ray diffraction experiments were carried out using a PANalytical X'Pert PRO Extended MRD diffractometer. The thickness was determined with a Brüker DektakXT stylus profi ler. Electron diffraction characterization was performed using a JEOL 3011 electron microscope.

The magnetotransport measurements were carried out using a physical property measurement system (PPMS). In order to fi t the sample into the PPMS sample holder, the inner part of the circuit (the central circle in Figure 3 a) was cut using an ultrasonic cutter.

\section{Acknowledgements}

This work was supported by the University of New South Wales and Spanish MICINN (Consolider CSD2007-0041). A portion of this work was performed at the ACT node of the Australian National Fabrication Facility. The authors wish to acknowledge Dr. F. Kremer for the electron diffraction measurement.

[1] B. J. Gans , P. C. Duineveld , U. S. Schubert , Adv. Mater. 2004 , 16 , 203.

[2] E. Tekin , P. J. Smith , U. S. Schubert , Soft Matter 2008, 4 , 703 .

[3] News: Katteva unveil their YIELDjet OLED TV inkjet printing system, http://www.kateeva.com (accessed: November 2013) .

[4] S. C. Chang , J. Liu , J. Bharathan , Y. Yang , J. Onohara , J. Kido , Adv. Mater. 1999 , 11 , 734 .

[5] T. Sekitani , H. Nakajima , H. Maeda , T. Fukushima , T. Aida , K. Hata , T. Someya , Nat. Mater. 2009, 8,494 .

[6] N. H. Claudia , A. C. Stelios , S. Pavel , J. B. Christoph , Adv. Mater. 2007 , 19 , 3973.

[7] N. H. Claudia , S. Pavel , A. C. Stelios , J. B. Christoph , Nano Lett. 2008 , 8, 2806.

[8] M. Hilder , B. Winther-Jensen , N. B. Clark , J. Power Sources 2009 , 194 , 1135.

[9] A. L. Briseno , S. C. B. Mannsfeld , M. M. Ling , S. Liu , R. J. Tseng , C. Reese , M. E. Roberts , Y. Yang , F. Wudl , Z. Bao , Nature 2006 , $444,913$.

[10] F. Antonio , Nat. Mater. 2013 , 12 , 598. 
[11] X. Obradors , T. Puig , Supercond. Sci. Technol. $2014,27,044003$.

[12] E. Bartolome , V. R. Vlad , A. Calleja , M. Aklalouch , R. Guzman , J. Arbiol , X. Granados , A. Palau , X. Obradors , T. Puig , A. Usoskin , Supercond. Sci. Technol. 2013 , 26 , 125004.

[13] M. Vilardell , X. Granados , S. Ricart , I. Van Driessche , A. Palau , T. Puig , X. Obradors , Thin Solid Films $2013,548,489$.

[14] M. Vilardell , X. Granados, S. Ricart , R. Cobas , M. Arjona , T. Puig , X. Obradors , S. C. Hopkins , B. A. Glowacki , J. Bennewitz, M. Falter , M. Backer , J. Imaging Sci. Technol. 2011 , $55,040304-1$.

[15] K. Y. Shin , J. Y. Hong , J. Jang , Adv. Mater. 2011 , 23 , 2113.

[16] H. Kozuka , J. Mater. Res. 2013 , 28, 673.

[17] T. T. Nge , M. Nogi , K. Suganuma , J. Mater. Chem. C 2013 , 1, 5235.

[18] K. Maejima , S. Tomikawa , K. Suzuki , D. Citterio , RSC Adv. 2013 , 3 , 9258.

[19] News: Panasonic unveil their 56" $4 \mathrm{~K}$ printed OLED TV prototype, http://www.oledinfo.com/panasonic-shows-56-4k-printed-oled-tvprototype (accessed: May 2014).

[20] J. Perelaer, U. S. Schubert, J. Mater. Res. $2013,28,564$.

[21] S. Gamerith , A. Klug , H. Scheiber , U. Scherf , E. Moderegger , E. J. W. List , Adv. Funct. Mater. $2007,17,3111$.

[22] P. Calvert, Chem. Mater. $2001,13,3299$.

[23] S. B. Fuller , E. J. Wilhelm , J. M. Jacobson , J. Microelectromech. Syst. $2002,11,54$.

[24] P. J. Smith , D. Y. Shin , J. E. Stringer , N. Reis , B. Derby , J. Mater. Sci. 2006 , 41 , 4153.

[25] J. S. Lee , Y. J. Kwack , W. S. Choi , ASC Appl. Mater. Interfaces 2013 , 5, 11578 .

[26] M. G. Kim , M. G. Kanatzidis , A. Facchetti , T. J. Marks , Nature Mater. 2011 , 10 , 382.

[27] J. Perelaer , P. J. Smith , D. Mager , D. Soltman , S. K. Volkman , V. Subramanian , J. G. Korvink, U. S. Schubert, J. Mater. Chem. $2010,20,8446$.

[28] B. Derby , Annu. Rev. Mater. Res. $2010,40,395$.

[29] B. A. Ridley , B. Nivi , J. M. Jacobson , Science 1999 , 286 , 746.

[30] D. B. Mitzi , L. L. Kosbar , C. E. Murray , M. Copel , A. Afzali , Nature 2004 , 428 , 299.

[31] T. Shimoda , Y. Matsuki , M. Furusawa , T. Aoki , I. Yudasaka , H. Tanaka , H. Iwasawa , D. Wang , M. Miyasaka, Y. Takeuchi , Nature $2006,440,783$.

[32] X. Obradors , T. Puig , M. Gibert , A. Queralto , J. Zabaleta, N. Mestres , Chem. Soc. Rev. $2014,43,2200$. 
[33] D. Sanchez-Rodriguez , J. Farjas , P. Roura , S. Ricart , N. Mestres , X. Obradors , T. Puig , J. Phys. Chem. C 2013, 117, 20133.

[34] P. Roura , J. Farjas , S. Ricart , M. Aklalouch , R. Guzman , J. Arbiol , T. Puig , A. Calleja , O. Peña-Rodríguez , M. Garriga , X. Obradors , Thin Solid Films 2012 , 520, 1949.

[35] A. Carretero-Genevrier , T. Puig , X. Obradors , N. Mestres, Chem. Soc. Rev. 2014, 43, 2042 .

[36] A. Queralto , A. P. del Pino , S. Ricart , X. Obradors , T. Puig , J. Alloys Compd. 2013 , 574 , 246 .

[37] G. H. Kim , H. S. Kim , H. S. Shin , B. D. Ahn , K. H. Kim , H. J. Kim , Thin Solid Films 2009 , 517,4007 .

[38] N. Bassiri-Gharb , Y. Bastani , A. Bernal , Chem. Soc. Rev. 2014 , 43 , 2125.

[39] T. M. McCleskey , P. Shi , E. Bauer, M. J. Highland, J. A. Eastman , Z. X. Bi , P. H. Fuoss , P. M. Baldo , W. Ren , B. L. Scott , A. K. Burrell , Q. X. Jia , Chem. Soc. Rev. 2014 , 43 , 2141.

[40] T. Nakajima , K. Shinoda , T. Tsuchiya , Chem. Soc. Rev. 2014 , 43 , 2027.

[41] Y. Tsuchiya , S. Haraguchi , M. Ogawa , T. Shiraki , H. Kakimoto , O. Gotou , T. Yamada , K. Okumoto, S. Nakatani , K. Sakanoue, S. Shinkai , Adv. Mater. 2012, $24,968$.

[42] J. Z. Wang , Z. H. Zheng, H. W. Li , W. T. S. Huck , H. Sirringhaus, Nat. Mater. 2004 , 3 , 171.

[43] S. H. Lee , K. Y. Shin , J. Y. Hwang , K. T. Kang , H. S. Kang , J. Micromech. Microeng. 2008 , 18,075014 .

[44] C. Tendero, Ch. Tixier , P. Tristant, J. Desmaison, P. Leprince, Spectrochim. Acta, Part B $2006,61,2$.

[45] T. Huiskamp , W. J. M. Brok , A. A. E. Stevens , E. J. M. van Heesch , A. J. M. Pemen , IEEE Trans. Plasma Sci. $2012,40,1913$.

[46] P. R. Pandey , S. Roy , J. Phys. Chem. Lett. 2013 , 4 , 3692.

[47] S. Poptoshev , P. M. Claesson , Langmuir 2002 , 18 , 2590.

[48] P. M. Claesson , O. E. H. Paulson, E. Blomberg , N. L. Burns , Colloids Surf. A 1997 , 123124,341 .

[49] H. F. Tan , B. Zhang , J. W. Yan , X. D. Sun , G. P. Zhang , Mater. Res. Bull. 2014 , 50 , 128.

[50] Z. Burghard, A. Tucic, L. P. H. Jeurgens, R. C. Hoffmann , J. Bill , F. Aldinger, Adv. Mater. $2007,19,970$.

[51] G. Decher , Science $1997,277,1232$. 
[52] R. Cobas , S. Muñoz-Perez , J. M. Cadogan , T. Puig , X. Obradors, Appl. Phys. Lett. 2011 , 99,831131 .

[53] M. H. Phan , S. Ch. Yu , J. Magn. Magn. Mater. 2007 , 308 , 325.

[54] M. Kar , S. Ravi , Mod. Phys. Lett. B 2004 , 18 , 221.

[55] M. B. Salamon , M. Jaime , Rev. Mod. Phys. 2001 , 73 , 583.

[56] D. R. Sabina , Y. Ning , Macromol. Rapid Commun. 2007 , 28 , 1934.

[57] R. D. Deegan , Phys. Rev. E $2000,61,475$.

[58] R. D. Deegan , O. Bakajin , T. F. Dupont, G. Huber , S. R. Nagel , T. A. Witten , Nature 1997, 389,827 .

[59] C. Moreno , P. Abellan , A. Hassini , A. Ruyter , A. P. del Pino , F. Sandiumenge , M. J. Casanove , J. Santiso , T. Puig , X. Obradors , Adv. Funct. Mater. 2009 , 19 , 2139.

[60] C. Moreno , C. Munuera , A. P. del Pino , J. Gutiérrez , T. Puig , C. Ocal , X. Obradors , A. Ruyter, Phys. Rev. B 2009, 80,094412 .

[61] K. J. Seu , A. P. Pandey , F. Haque , E. A. Proctor , A. E. Ribbe , J. S. Hovis, Biophys. J. 2007 , 92,2445 .

[62] M. A. C. Stuart , G. J. Fleer , J. Lyklema , W. Norde , J. M. H. M. Scheutjens , Adv. Colloid Interface Sci. $1991,34,477$. 